\title{
Ascending and Descending Thoracic Vertebral Arteries
}

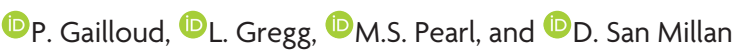

\begin{abstract}
SUMMARY: Thoracic vertebral arteries are anastomotic chains similar to cervical vertebral arteries but found at the thoracic level. Descending thoracic vertebral arteries originate from the pretransverse segment of the cervical vertebral artery and curve caudally to pass into the last transverse foramen or the first costotransverse space. Ascending thoracic vertebral arteries originate from the aorta, pass through at least 1 costotransverse space, and continue cranially as the cervical vertebral artery. This report describes the angiographic anatomy and clinical significance of 9 cases of descending and 2 cases of ascending thoracic vertebral arteries. Being located within the upper costotransverse spaces, ascending and descending thoracic vertebral arteries can have important implications during spine interventional or surgical procedures. Because they frequently provide radiculomedullary or bronchial branches, they can also be involved in spinal cord ischemia, supply vascular malformations, or be an elusive source of hemoptysis.
\end{abstract}

ABBREVIATIONS: ISA = intersegmental artery; SIA = supreme intercostal artery; VA = vertebral artery

$\mathrm{T}$ he cervical portion of the vertebral artery (VA) is formed by a series of anastomoses established between the first 6 cervical intersegmental arteries (ISAs) and one of the carotid-vertebral anastomoses, the proatlantal artery. ${ }^{1-3}$ The VA is labeled a "postcostal" anastomotic chain (ie, located behind the costal process of cervical vertebrae or dorsal to the rib itself at the thoracic level) to emphasize its location within the transverse foramina. A thoracic VA is a similar postcostal vessel found at the thoracic level. ${ }^{4}$

A thoracic VA was originally defined as a proximal VA branch curving medially and caudally to enter the ipsilateral C7 transverse foramen or first costotransverse space (Fig 1, right). ${ }^{5}$ Atypical forms, common in birds and mammals but rare in humans, ${ }^{5,6}$ include thoracic VAs originating from the supreme intercostal or deep cervical arteries.

Another anastomotic chain found within the upper costotransverse spaces differs from a descending thoracic VA by its caudal origin from a thoracic ISA and its ascending course. ${ }^{7}$ This exceptional variant corresponds to an ascending thoracic VA (Fig 1 , left) and should not be confused with variants such as a verte-

Received August 5, 2016; accepted after revision September 23.

From the Division of Interventional Neuroradiology (P.G., L.G., M.S.P., D.S.M.), The Johns Hopkins Hospital, Baltimore, Maryland; and Neuroradiology Unit (D.S.M.), Service of Diagnostic and Interventional Radiology, Sion Hospital, Centre Hospitalier du Valais Romand, Romand, Switzerland.

Please address correspondence to P. Gailloud, MD, Division of Interventional Neuroradiology, The Johns Hopkins Hospital, 1800 E Orleans St, Bloomberg 7218 Baltimore, MD 21287; e-mail: phg@jhmi.edu

http://dx.doi.org/10.3174/ajnr.A5016 bral arteria lusoria ${ }^{8-13}$ or persistent left seventh cervical ISA of aortic origin. $^{14}$

This report discusses 9 angiographic observations of descending thoracic VAs and 2 cases of ascending thoracic VAs.

\section{CASE SERIES}

\section{Descending Thoracic Vertebral Arteries}

Nine typical descending thoracic VAs were documented by DSA in 9 patients between 2006 and 2015 (Table). The variation was unilateral in 8 instances. In 1 patient, a contralateral thoracic VA was documented by CTA only. The bifurcation into the cervical and thoracic VAs was found at C7-T1 (5 instances, 56\%) or C6-C7 (4 instances, 44\%). The descending thoracic VA was right-sided in 8 cases (89\%).

The ISAs provided by the descending thoracic VAs were either complete (ie, including medial, dorsal, and lateral branches) or incomplete, with only the medial branch present; the other branches then came from the supreme intercostal artery (SIA). Most commonly, the descending thoracic VA provided the second (T2) and third (T3) thoracic ISAs completely, as well as 1 or more partial ISA proximally (T1 in 5 cases, $\mathrm{C} 7$ and $\mathrm{T} 1$ in 1 case). Isolated medial branches were also noted at $\mathrm{C} 7$ or $\mathrm{T} 2$ (once each). In 2 observations, the descending thoracic VAs were extending out of the FOV after branching off the third thoracic ISA (T3). Descending thoracic VAs branched off important anterior radiculomedullary arteries in 5 instances (56\%), 4 times at T2 and once at T1. 
Case 1. Right descending thoracic VA documented (Fig 2) in a 64-year-old man.

Case 2. Right descending thoracic VA documented in a 67-yearold woman (Fig 3).

Case 3. Bilateral descending thoracic VAs documented in a 59year-old woman (Fig 4).

Case 4. Right descending thoracic VA documented in 30-year-

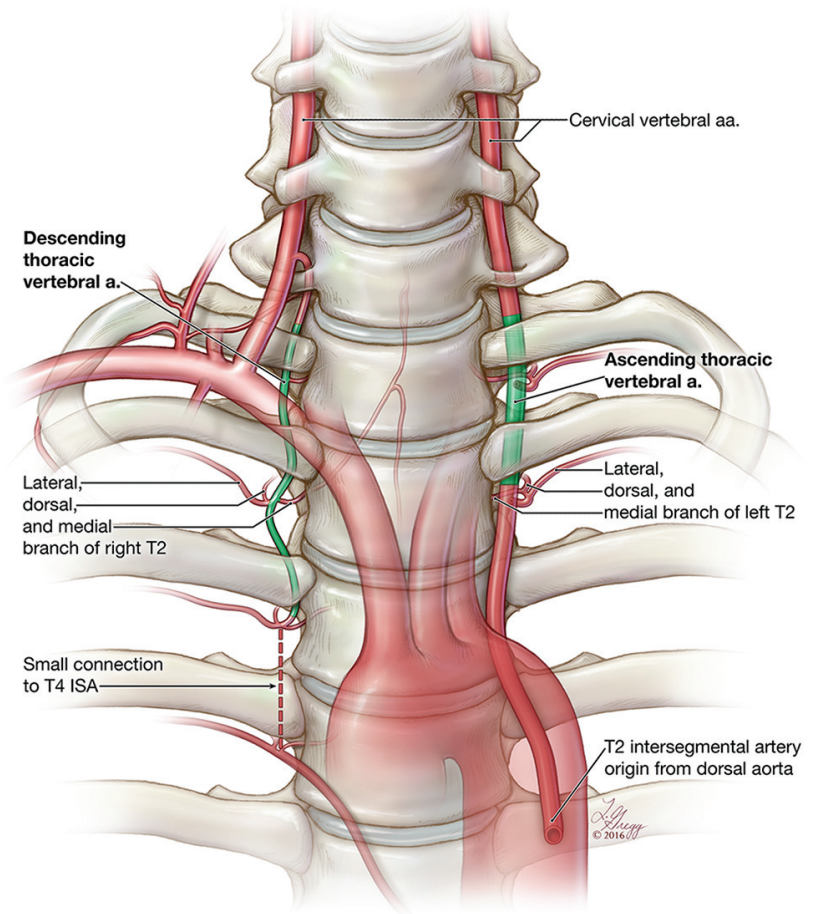

FIG 1. Schematic representation of ascending and descending thoracic vertebral arteries. In its most typical form, a descending thoracic VA (right side) originates from the pretransverse segment (VI) of the cervical VA and curves sharply medially and caudally to enter the last transverse foramen or the first costotransverse space. It then continues caudally, passing through 1 or more costotransverse space, generally branching off a complete set of branches for the second and third thoracic ISAs (T2 and T3) and the medial branch of the first thoracic ISA (TI). In about $50 \%$ of cases, a descending thoracic VA provides an important contribution to the spinal cord vascularization. An ascending thoracic VA (left side) is the cranial prolongation of a thoracic ISA, which passes through 1 or more costotransverse space before continuing as a normal cervical VA. Strictly speaking, the thoracic $V A$ segment only corresponds to the portion of the vessel delimited by costotransverse spaces (highlighted in green). old man (Fig 5A, -B). An ipsilateral costocervical angiogram illustrates the characteristics distinguishing a descending thoracic VA from an SIA (Fig $5 C,-D$ ).

Case 5. A 47-year-old woman with a right descending thoracic VA branching off the third thoracic ISA as well as a conspicuous bronchial artery (Fig 6).

\section{Ascending Thoracic Vertebral Arteries}

Case 1. A 20-year-old man with bullet fragments in the posterior fossa. The right VA injection showed minimal reflux into the left V4 segment, with prompt wash-off indicating the presence of a patent left VA, which was identified as the cranial continuation of the left T2 ISA (Fig 7A, -B). Enlargement of the left T1 and T2 costotransverse spaces was noted (Fig 7C).

Case 2. A 64-year-old man investigated for gait disturbance. A left VA originating from the thoracic aorta and passing through the left T2 and T1 costotransverse spaces (Fig 8A) is identified as a left T2 ISA (Fig 8B).

\section{DISCUSSION}

\section{Developmental Anatomy of the VA}

His $^{15}$ divided the VA into cranial and cervical portions on the basis of their developmental history. Appearing first, the cranial portion principally consists of the proatlantal artery, which is associated with the first cervical nerve. The anterior radiculomedullary branch stemming from the proatlantal artery becomes the distal VA; it divides into ascending and descending rami, which respectively turn into the proximal basilar artery and the vertebral root of the anterior spinal artery. ${ }^{16-18}$ The cervical portion of the VA subsequently forms as a succession of anastomoses between the first 6 ISAs, which connect cranially with the proatlantal artery and caudally with the subclavian artery (sixth ISA). ${ }^{2}$ The final configuration of the VA depends on which primitive ISA becomes its adult origin. Most often, the proximal VA, being derived from the sixth cervical ISA, originates from the subclavian artery and enters the $\mathrm{C} 6$ transverse foramen. Variations are identified by the level at which they enter the transverse canal rather than by their origin. For example, a VA derived from the seventh cervical ISA always enters the $\mathrm{C} 7$ transverse foramen but can arise from the aorta or from the subclavian artery via the SIA. ${ }^{19}$

A thoracic VA is an anastomotic chain passing through 1 or more costotransverse space. ${ }^{4,19}$

\section{Nine angiographic observations of the descending thoracic vertebral artery}

\begin{tabular}{|c|c|c|c|c|c|c|c|c|}
\hline \multirow[b]{2}{*}{ Patient } & \multirow[b]{2}{*}{ Sex } & \multirow{2}{*}{$\begin{array}{l}\text { Age } \\
\text { (yr) }\end{array}$} & \multirow[b]{2}{*}{ Level } & \multirow[b]{2}{*}{ Side } & \multicolumn{2}{|c|}{ ISA } & \multicolumn{2}{|c|}{ Branches } \\
\hline & & & & & Complete & Partial & ARMA & $\mathrm{Br}$ \\
\hline 1 & $M$ & 64 & $\mathrm{C} 7-\mathrm{Tl}$ & $R$ & T2-T3 & Medial C7-T1 & $\mathrm{T} 2$ & Yes \\
\hline 2 & W & 67 & C7-T1 & $\mathrm{R}$ & $\mathrm{T} 2-\mathrm{T} 4 ?^{\mathrm{a}}$ & Medial $\mathrm{T}\rceil$ & $\mathrm{Tl}$ & No \\
\hline 3 & W & 59 & C6-C7 & $\mathrm{L}$ & $\mathrm{T} 2-\mathrm{T} 3$ & Medial T1 & $\mathrm{T} 2$ & No \\
\hline 4 & $M$ & 30 & C6-C7 & $\mathrm{R}$ & $\mathrm{T} 2$ & Medial C7 & $\mathrm{T} 2$ & No \\
\hline 5 & W & 47 & $\mathrm{C} 6-\mathrm{C} 7$ & $\mathrm{R}$ & $\mathrm{T} 3$ & Medial T2 & - & Yes \\
\hline 6 & $M$ & 18 & $\mathrm{C} 7-\mathrm{Tl}$ & $\mathrm{R}$ & $\mathrm{T} 2-\mathrm{T} 3$ & Medial T1 & $\mathrm{T} 2$ & No \\
\hline 7 & W & 56 & C7-T1 & $\mathrm{R}$ & $\mathrm{T} 2-\mathrm{T} 3$ & Medial Tा & - & No \\
\hline 8 & W & 60 & C7-TI & $\mathrm{R}$ & $\mathrm{T} 2-\mathrm{T} 4 ?^{\mathrm{a}}$ & Medial T1 & - & No \\
\hline 9 & W & 31 & C6-C7 & $\mathrm{R}$ & $\mathrm{T1}-\mathrm{T} 2$ & $?^{\mathrm{b}}$ & - & No \\
\hline
\end{tabular}

Note:-ARMA indicates anterior radiculomedullary artery; Br, bronchial artery; R, right; L, left; -, none; M, man; W, woman.

${ }^{a}$ Question mark indicates that the caudal extension of the descending thoracic VA was beyond the FOV

${ }^{\mathrm{b}}$ Question mark indicates that motion artifacts prevented evaluating the presence of a proximal medial branch. 

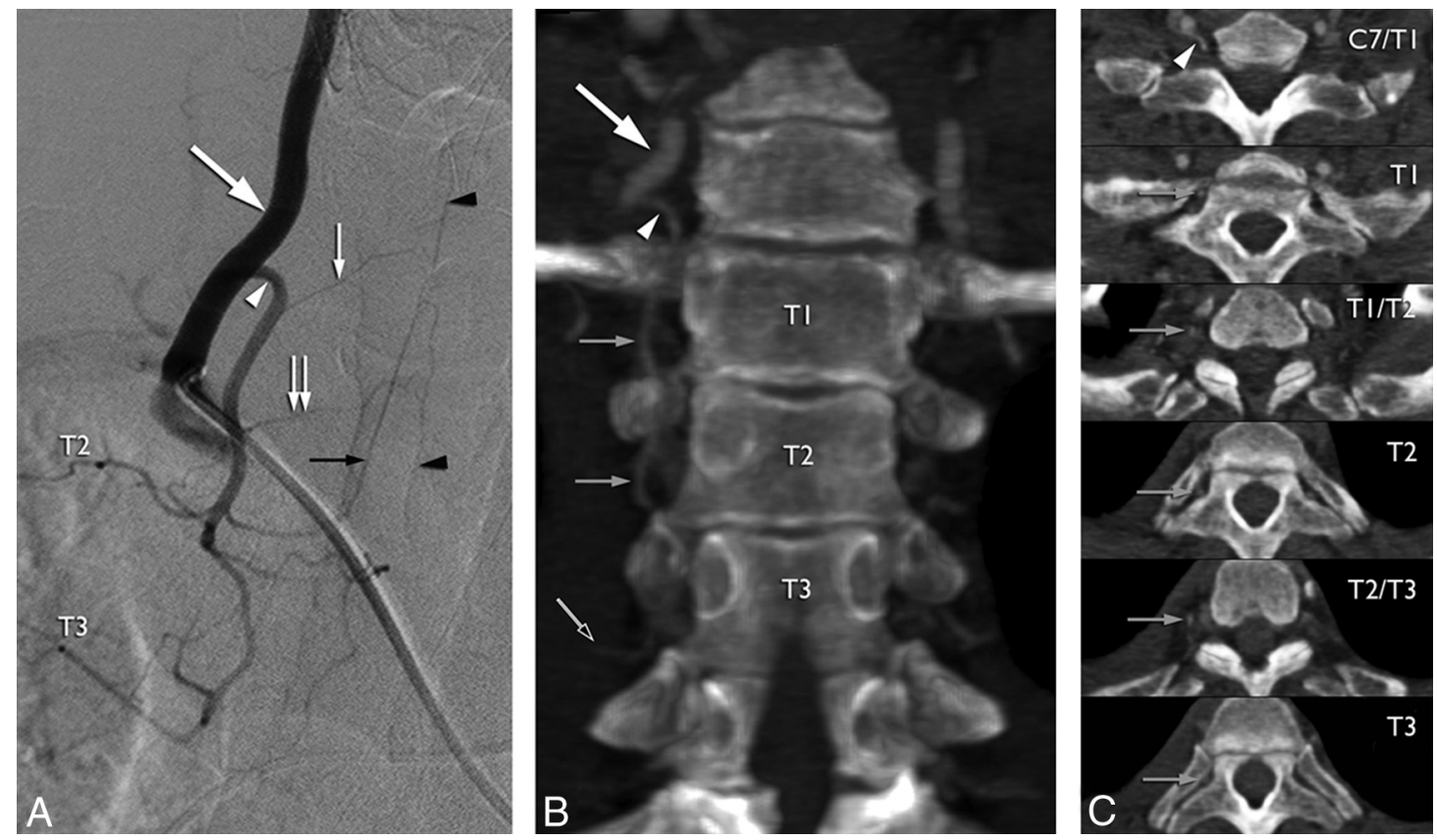

FIG 2. A 64-year-old man with a right descending thoracic vertebral artery. A, DSA, right VA injection, posteroanterior projection, shows a VA originating from the subclavian artery and dividing into ascending cervical (large white arrow) and descending thoracic (white arrowhead) VAs at the C7-T7 level. The descending thoracic VA provides the medial branches of C7 (small white arrow) and 77 (double small white arrow) and complete sets of branches for the T2 and T3 ISAs. The second thoracic ISA provides a prominent anterior radiculomedullary artery (small black arrow), which supplies the anterior spinal artery (black arrowheads). B, CTA, coronal reconstruction at the level of the transverse foramina. The ascending (large white arrow) and descending (white arrowhead) branches of the VA are identified. The small gray arrows point to the descending thoracic VA down to its termination at T3 (small black arrow). C, CTA, multilevel axial reconstructions, shows the course of the descending thoracic VA (small gray arrows) from its origin at C7-Tा (white arrowhead).
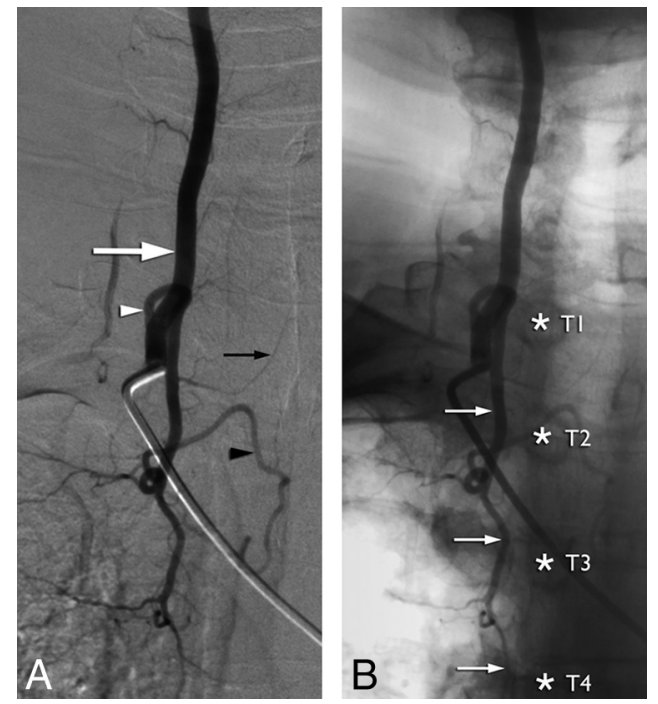

FIG 3. A 67-year-old woman with a right descending thoracic vertebral artery. A, DSA, right VA injection, posteroanterior projection. The VA divides into ascending cervical (large white arrow) and descending thoracic (white arrowhead) VAs at the C7-T level. The descending thoracic VA provides the medial branch of $\mathrm{T}$, which gives off a prominent anterior radiculomedullary artery (small black arrow). Note that the descending thoracic VA extends beyond the FOV and may provide additional ISAs. A prominent T2 dorsal (muscular) branch is seen coursing medially and caudally (black arrowhead) and should not be confused with a bronchial artery. B, DSA, right VA injection, nonsubtracted posteroanterior projection, documents the close relationship between the descending thoracic VA and the cervical pedicles (asterisks), notably at the level of the transverse foramina (small white arrows).
Walsham ${ }^{4}$ described thoracic VAs in the following manner: "The artery would here appear to be homologous to the vertebral artery in the neck, as both lie between homologous parts, the anterior part of the transverse process of the cervical vertebra being the homolog of the neck and head of the dorsal rib, and the posterior part of the cervical transverse process that of the transverse process of the dorsal vertebra."

While any postcostal anastomosis established between 2 or more thoracic ISAs answers this definition (eg, a T3-T4 intercostal trunk linked by a postcostal anastomosis), the term "thoracic VA" is generally reserved for variants connected with or continuing as a cervical VA. These variations can be divided into 2 groups with similar developmental mechanisms but different connection patterns: the ascending and descending thoracic VAs. Descending thoracic VAs generally share a common origin with the cervical VA but may also be connected to the SIA or deep cervical artery (atypical forms of Krassnig ${ }^{5}$ ) (Figs 9 and 10, right). ${ }^{20}$ An alternate configuration reported by Bühler ${ }^{21}$ consists of a first thoracic ISA originating from the aorta and continuing as a descending thoracic VA to branch off additional ISAs (Fig 10, left).

Ascending thoracic VAs arise from the thoracic aorta and continue cranially as a cervical VA. ${ }^{7}$ A thoracic VA can occasionally show mixed characteristics by connecting both at the cervical and thoracic levels (eg, Walsham's case $\left.{ }^{4}\right){ }^{7}$ Dubreuil-Chambardel ${ }^{7}$ reviewed the cases of ascending and descending thoracic vertebral arteries published before 1926 .

Two configurations developmentally similar to thoracic VAs must be distinguished from this group of variations because they fail to pass through at least 1 costotransverse space. These include more 

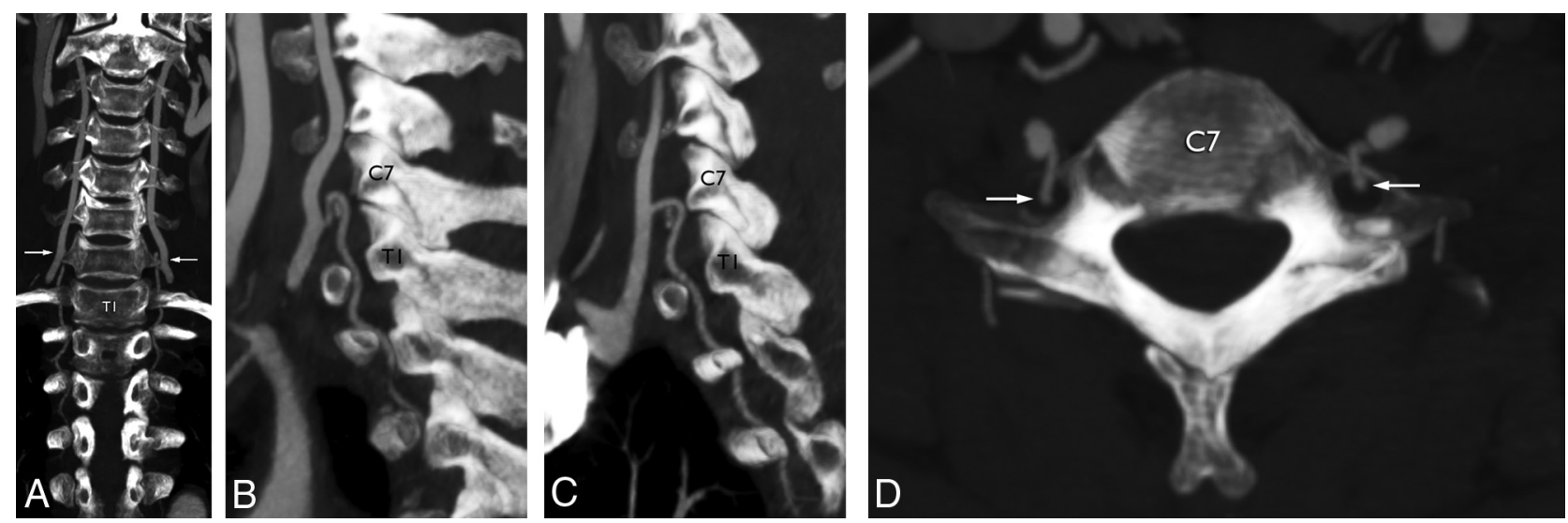

FIG 4. A 59-year-old woman with bilateral descending thoracic vertebral arteries. A, CTA, coronal reconstruction at the level of the transverse foramina, documents bilateral and symmetric descending thoracic VAs, both originating at C6-C7 (arrows) and ending at T4 on the right and T3 on the left. B, CTA, sagittal reconstruction at the level of the left transverse foramina. Note that the level of the variant (C6-C7) is indicated by its tight curve over the anterior margin of the transverse foramen rather than by the actual level of the bifurcation of the common VA trunk (C7-TT). C, CTA, sagittal reconstruction at the level of the right transverse foramina. D, CTA, axial reconstruction, shows the sharp posterior turn of the descending thoracic VA to pass through the C7 transverse foramina (white arrows).
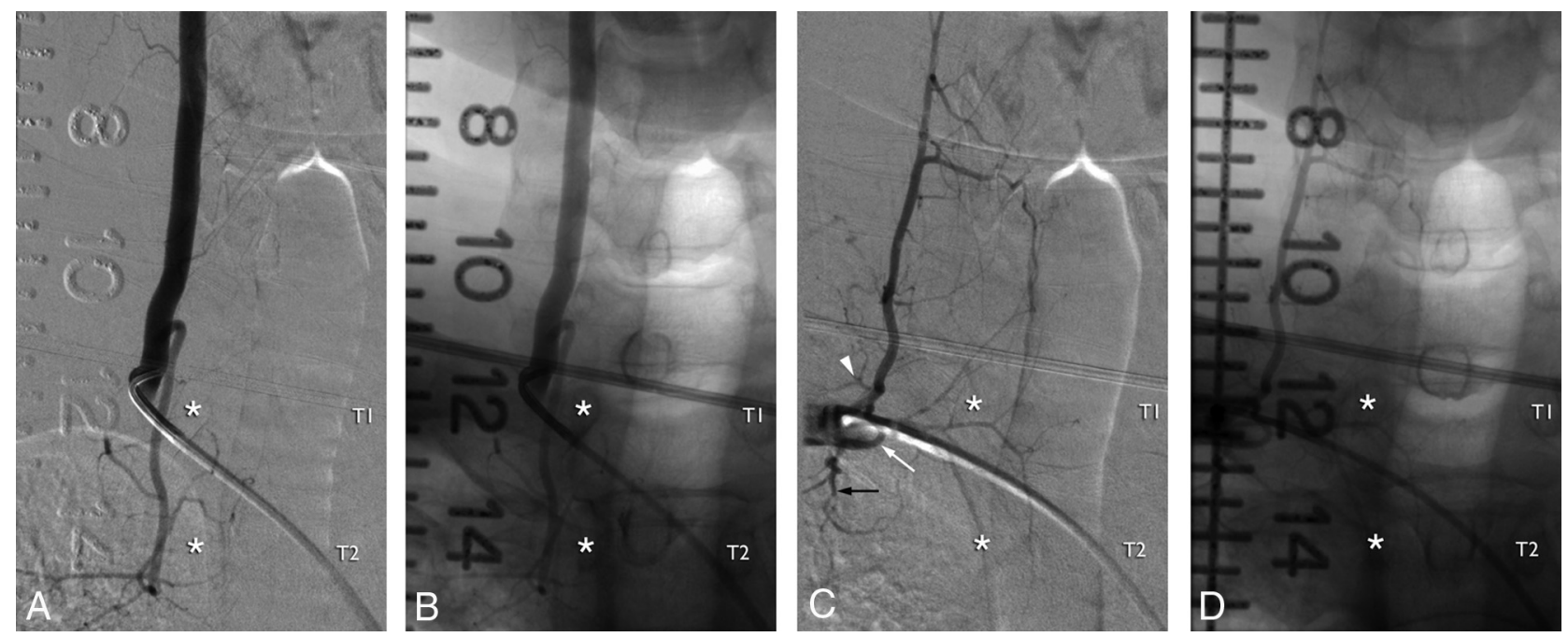

FIG 5. A 30-year-old man with a right-sided descending thoracic vertebral artery. A, DSA, right VA injection, posteroanterior projection, subtracted view. Note the typical appearance of the descending thoracic VA, which provides, in this case, medial branches for C7 and Tl and a full set of intersegmental braches for T2 (the asterisks indicate the right T1 and T2 pedicles in all images). B, DSA, right VA injection, posteroanterior projection, nonsubtracted view. C, DSA, right costocervical trunk injection, posteroanterior projection, subtracted view. The existence of a supreme intercostal artery (white arrow) is independent of the presence of a descending thoracic VA. In this case, the supreme intercostal artery provides the C7 ISA (arrowhead) and the lateral branch of the T1 ISA (black arrow). D, DSA, right costocervical trunk injection, nonsubtracted posteroanterior projection. Contrary to a descending thoracic VA, the supreme intercostal artery lies away from the vertebral pedicles (hence outside the costotransverse spaces).

cranially bifurcating trunks with a descending branch that remains within the cervical region (Fig 11A) and VAs of aortic origin entering the seventh transverse foramen (Fig 11B). The latter corresponds to persistent seventh cervical ISAs; their aortic origin remains close to the left subclavian artery. ${ }^{14}$ A vertebral arteria lusoria ${ }^{8}$ (ie, a right VA originating distal to the left subclavian artery) also known as a "distal aortic origin of the VA" or "fourth branch of the aortic arch," "13 must be distinguished from a thoracic VA as well (though a vertebral arteria lusoria of low origin with a thoracic component is conceivable but, to our knowledge, not reported).

\section{Descending Thoracic Vertebral Arteries}

The first case of a descending thoracic VA known to the authors was reported by Quain in 1844 (Fig 12). ${ }^{22}$ Pensa $^{23}$ confirmed the observation of Quain in 1905 and documented the concomitant existence of thoracic VAs and SIAs (Fig 13). Approximately 70 years later, Newton and $\mathrm{Mani}^{24}$ offered the first angiographic documentation of a descending thoracic VA (labeled as a "vertebral origin of the SIA"), while Chiras et $\mathrm{al}^{25}$ published a correctly identified bilateral observation in 1982.

It is important to distinguish descending thoracic VAs from SIAs (both are usually present simultaneously ${ }^{19}$ ). A major difference is topographic in nature: A thoracic VA is a postcostal vessel passing through costotransverse spaces, while an SIA is a precostal vessel lying in a more lateral position (Figs 1 and 5). Other variations that should not be confused with a descending thoracic VA include VAs originating from the SIA via the seventh cervical ISA (which is often mislabeled as an SIA or costocervical trunk origi- 
nating from the VA) (Fig 14) and aberrant bronchial arteries arising from the proximal VA (Fig 15). On the other hand, a VA originating from the SIA via a thoracic ISA (eg, T1 or T2) and entering the first or second costotransverse space would represent an atypical form of an ascending thoracic VA.

Note that in Pensa's illustration, ${ }^{23}$ the descending thoracic VA does not give off the lateral branch of T1 (Fig 8). This observation

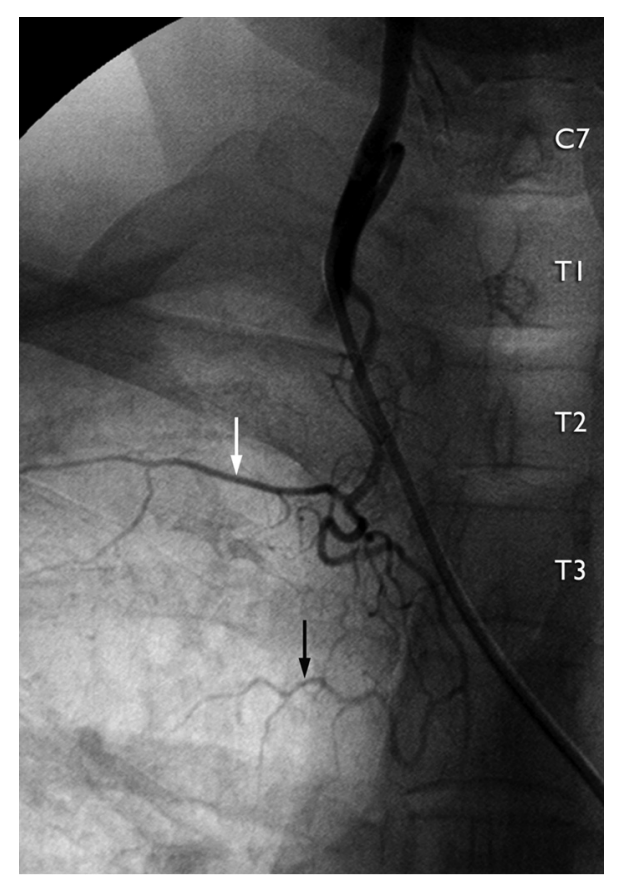

FIG 6. A 47-year-old woman with a right descending thoracic VA. This typical descending thoracic VA provides, in addition to the second thoracic ISA (white arrow), a prominent bronchial artery (black arrow).
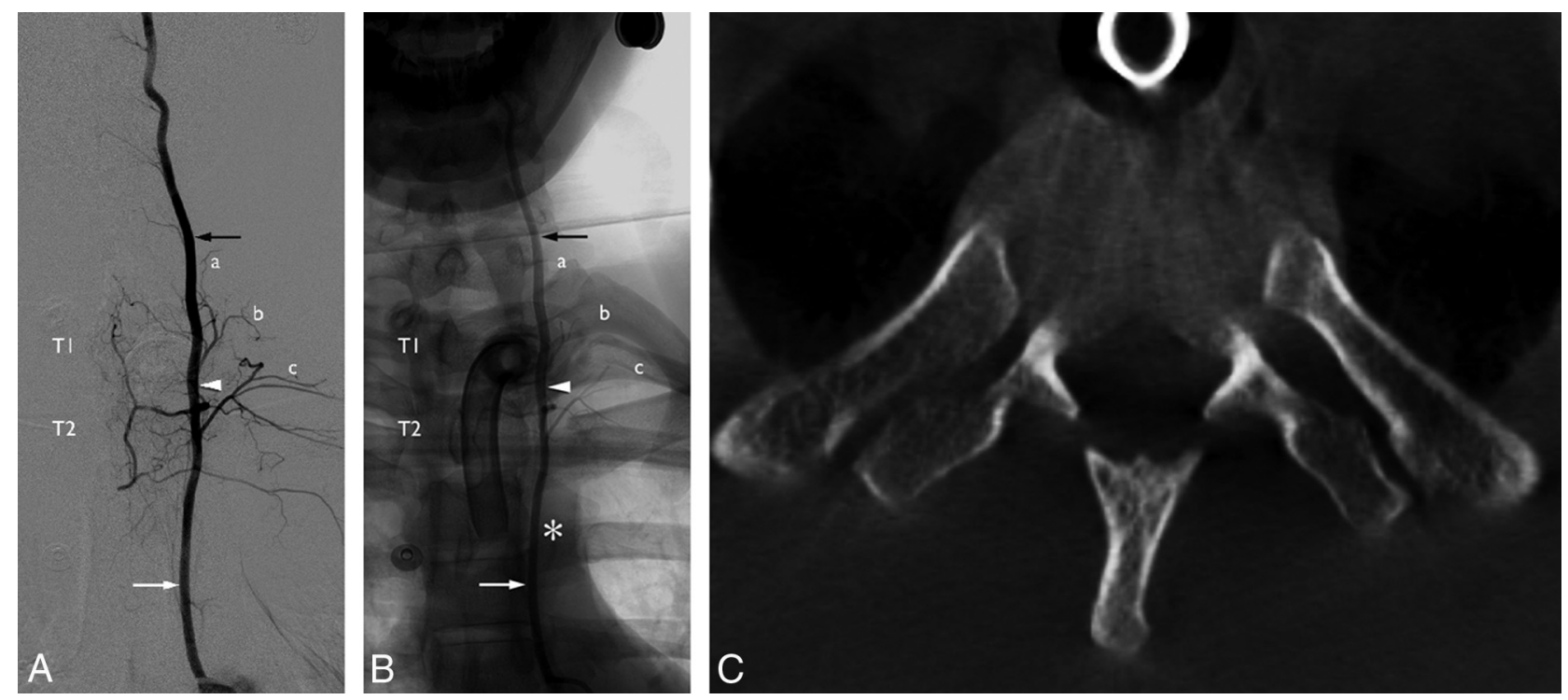

FIG 7. A 20 -year-old man with a left ascending thoracic VA. A, DSA, left T2 ISA injection, posteroanterior projection, subtracted view. The T2 ISA (white arrow) provides the second intercostal artery (c) before crossing through the T2 costotransverse space (white arrowhead). It then branches off contributions for the Tl (b) and C7 (a) ISAs and continues cranially as the cervical VA (black arrow). B, DSA, left T2 ISA injection, posteroanterior projection, nonsubtracted view. The asterisk indicates the approximate level of the origin of the left subclavian artery from the aortic arch, illustrating the distance separating the latter from the left T2 ostium. C, CT, axial view at the T2 level, shows a marked asymmetry of the size of the T2 costotransverse spaces. This sign should be taken into consideration when planning an upper thoracic spine procedure-for example, when choosing a needle path for a vertebral biopsy or a vertebroplasty. 

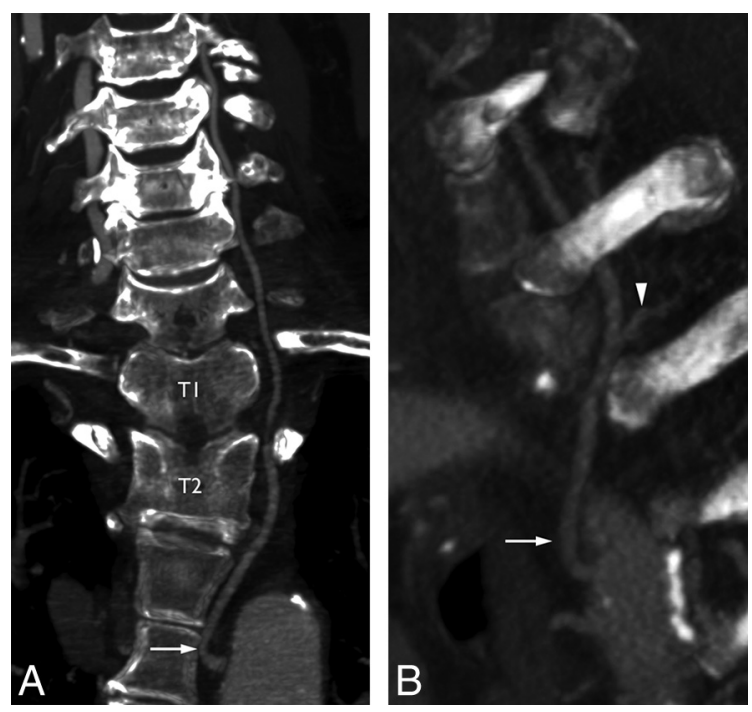

FIG 8. A 64-year-old man with a left ascending thoracic VA. A, CTA, coronal MIP reconstruction, shows the origin of the left T2 ISA (white arrow) and its passage through the $\mathrm{T} 2$ and $\mathrm{Tl}$ costotransverse spaces. The vessel then continues cranially as the cervical VA. B, CTA, oblique MIP reconstruction, documents the T2 posterior intercostal artery (arrowhead), therefore identifying the ascending thoracic VA as being derived from the second thoracic ISA (arrow).
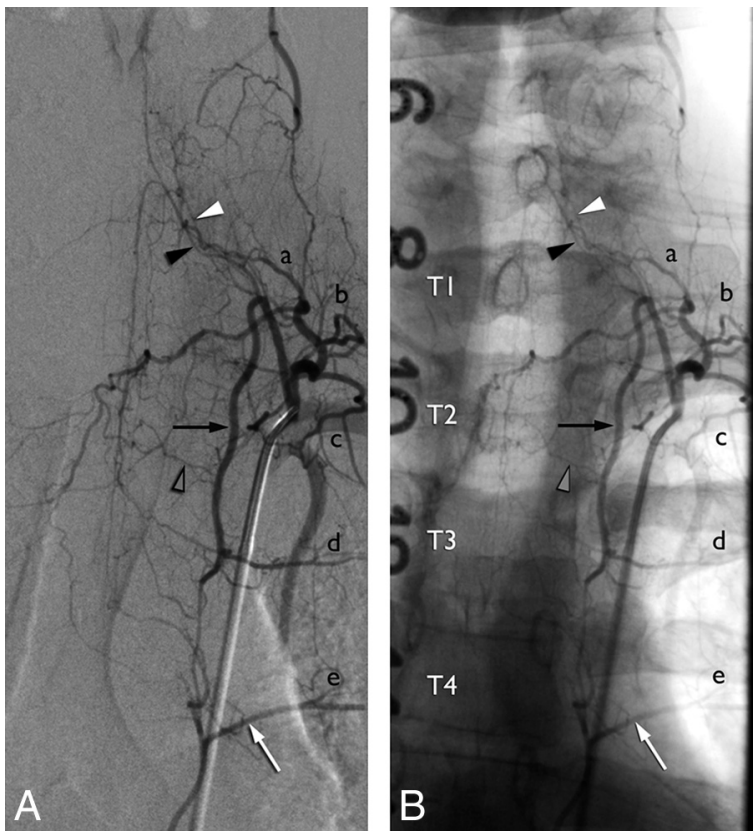

FIG 9. A 31-year-old woman with an atypical descending thoracic VA. A, DSA, left supreme intercostal artery injection, posteroanterior projection, subtracted view shows an example of a descending thoracic VA originating from the supreme intercostal artery (atypical form of Krassnig $g^{5}$; in this case, there is no connection with the cervical VA. The supreme intercostal artery provides the $\mathrm{C} 7(\mathrm{a})$ and $\Pi$ (b) ISAs as well as the lateral branch of the T2 ISA (c). A prominent ascending branch curves sharply downward to enter the first costotransverse space and continues caudally as a descending thoracic VA (black arrow) passing through the $\mathrm{T} 2$ and $\mathrm{T} 3$ the costotransverse spaces. This descending thoracic VA provides the T3ISA (d) and the medial branch of the T2 ISA (gray arrowhead). Note the opacification of the T4 ISA (e) via a small paravertebral anastomotic connection (as shown in Fig 1, right side). The C7 ISA provides both an anterior (black arrowhead) and a posterior (white arrowhead) radiculomedullary artery. B, DSA, left supreme intercostal artery injection, posteroanterior projection, nonsubtracted view of same image.

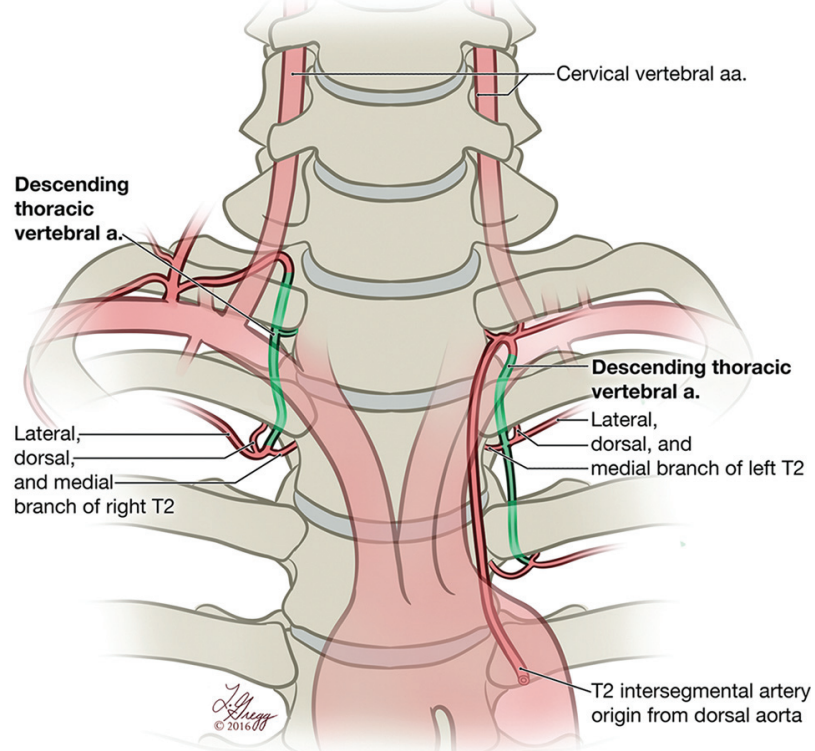

FIG 10. Schematic representation of 2 types of descending thoracic VA variants. The descending thoracic VA (atypical form of Krassnig ${ }^{5}$ ) depicted on the right side is, as in Fig 9, connected with the supreme intercostal artery rather than the cervical VA. In the configuration shown on the left side (atypical form of Bühler ${ }^{27}$ ), the descending thoracic VA is the downward continuation of a thoracic ISA of aortic origin. a. indicates artery.
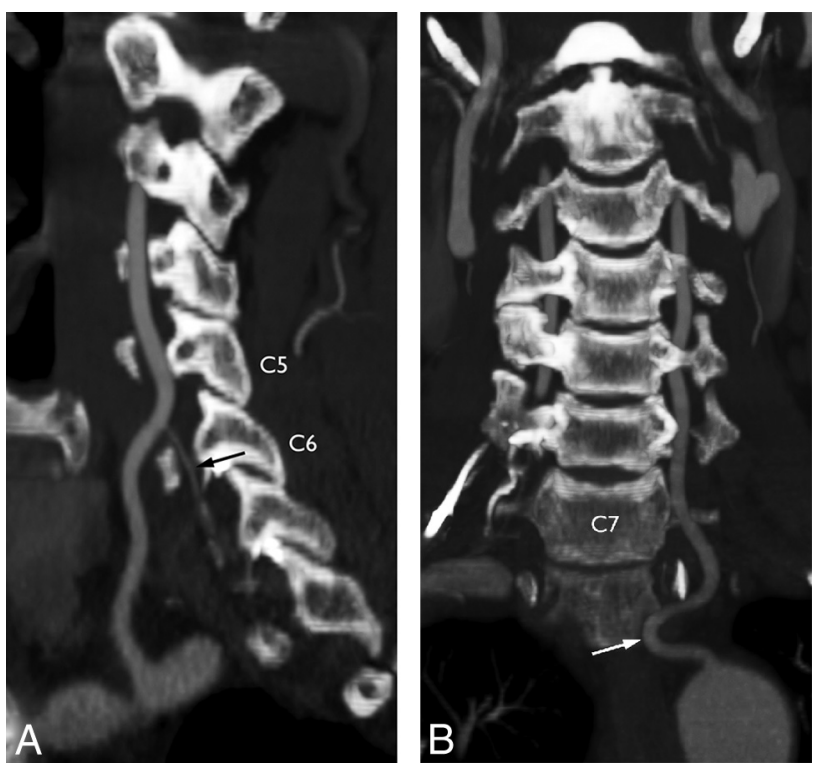

FIG 11. Examples of vertebral configurations similar to but distinct from thoracic VAs. A, CTA, sagittal MIP reconstruction. This case shows a descending branch with an appearance similar to that of a descending thoracic VA (arrow). However, the bifurcation is located at $\mathrm{C} 5-\mathrm{C6}$, and the descending branch stops at $\mathrm{C}$, short of the first costotransverse space. There is, therefore, no thoracic segment. $B$, CTA, coronal MIP reconstruction, shows a vertebral artery originating from the aorta distal to the subclavian artery and entering the seventh transverse foramen (arrow). This vessel corresponds to a persistent seventh ISA and has no thoracic component.

in the European pond turtle are branches of an anastomotic chain similar in nature to a $\mathrm{VA},{ }^{23}$ an observation suggesting that such extensive longitudinal vertebral chains may, as extreme variants, exist in humans as well. 


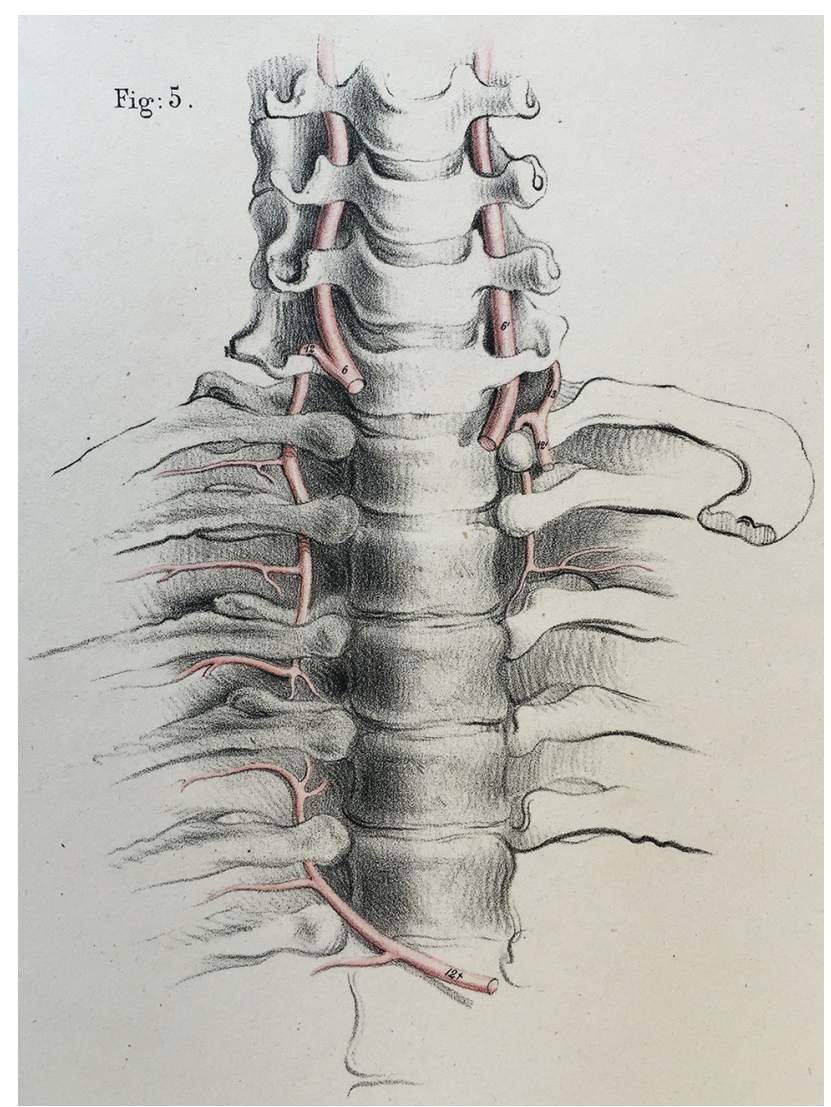

FIG 12. First known representation of a descending thoracic vertebral artery by Joseph Maclise for Richard Quain in 1844 (Fig 5, Plate XXII). ${ }^{22}$ The figure accurately depicts a typical descending thoracic VA on the right side (12) and an atypical form on the left $\left(12^{\prime}\right)$, as later defined by Krassnig. ${ }^{5}$ While both vessels are clearly coursing within the costotransverse spaces, the distinction from the supreme (or superior) intercostal arteries has not yet been established. The original legend is the following: "The left vertebral enters the last cervical vertebra. On the right side the superior intercostal artery is derived from the vertebral, and passes downwards into the thorax through the foramen in the transverse process of the seventh cervical vertebra, and afterward between the necks of the ribs and the corresponding transverse processes of the dorsal vertebræ. It will be observed that the superior intercostal of the other side descends also between the ribs and the processes of the vertebræ; and that the first aortic intercostal branch occupies a similar position in reference to the bones." 6 indicates right vertebral, $6^{\prime}$, left vertebral; 12, right superior intercostal; 12', left superior intercostal; 12†, first aortic intercostal; 13, deep cervical (arteria profunda cervicis).

\section{Clinical Relevance}

Spine surgeons and interventionists must be aware of the existence of thoracic VAs because their injury during a vertebral procedure may prove significant, notably in cases of ascending thoracic VAs supplying the posterior fossa. One or more abnormally conspicuous costotransverse space may be the only sign indicating the presence of such a variant on preoperative imaging (Fig 7C).

These variants also have a significant angiographic importance. Thoracic VAs may, through one of their frequent radiculomedullary branches, supply a spinal vascular malformation or be involved in the development of spinal cord ischemia. Similarly, because ascending thoracic VAs participate in the vascularization of the posterior fossa, they may play a role in vertebrobasilar in-

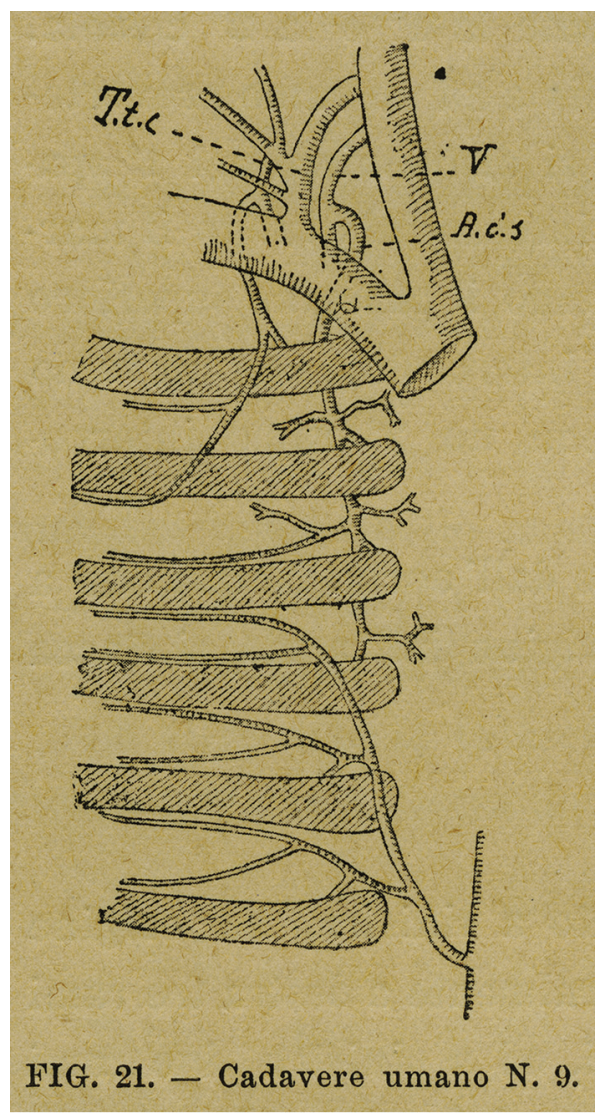

FIG 13. Reproduction of the original Fig 21 of Pensa, ${ }^{23}$ showing an example of a typical descending thoracic VA providing $T 1$ partially and T2 entirely. The supreme intercostal artery (originating from an unlabeled costocervical trunk) is clearly distinguished from the thoracic VA, both in the illustration and in the Pensa's text, the latter emphasizing the respective precostal and retrocostal locations of the 2 vessels. However, the nomenclature remains uncertain; Pensa labeled the descending thoracic VA as an arteria intercostalis suprema (A.i.s). V indicates vertebral artery; T.t.c, thyrocervical trunk.
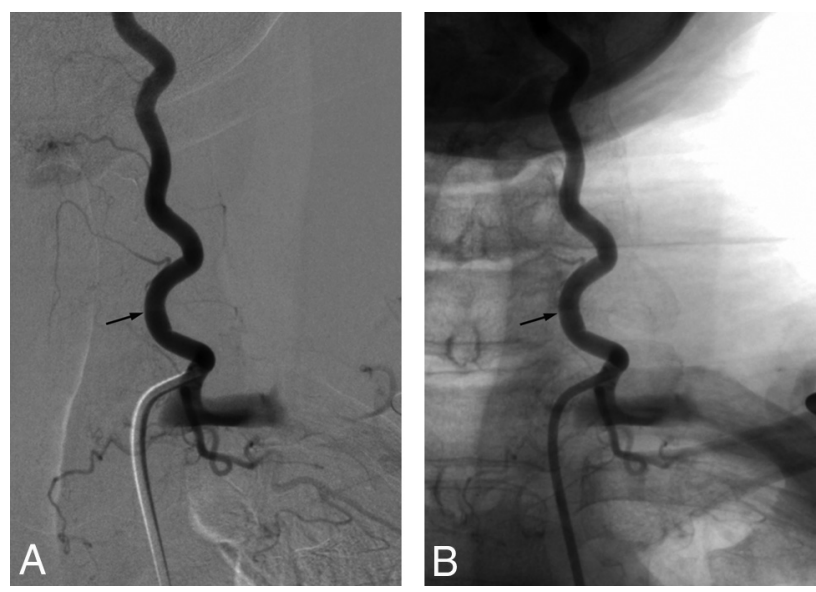

FIG 14. Vertebral artery variant in a 55-year-old woman. This left vertebral injection (posteroanterior projection, subtracted, $A$, and nonsubtracted, $B$, images) documents a vertebral artery that originates from the supreme intercostal artery (ie, a persistent seventh ISA) and enters the transverse canal at C7 (arrow). Because the vertebral artery becomes dominant in the adult stage, it falsely suggests an opposite relationship (ie, a supreme intercostal artery of vertebral origin).

AJNR Am J Neuroradiol 38:327-35 Feb 2017 www.ajnr.org 


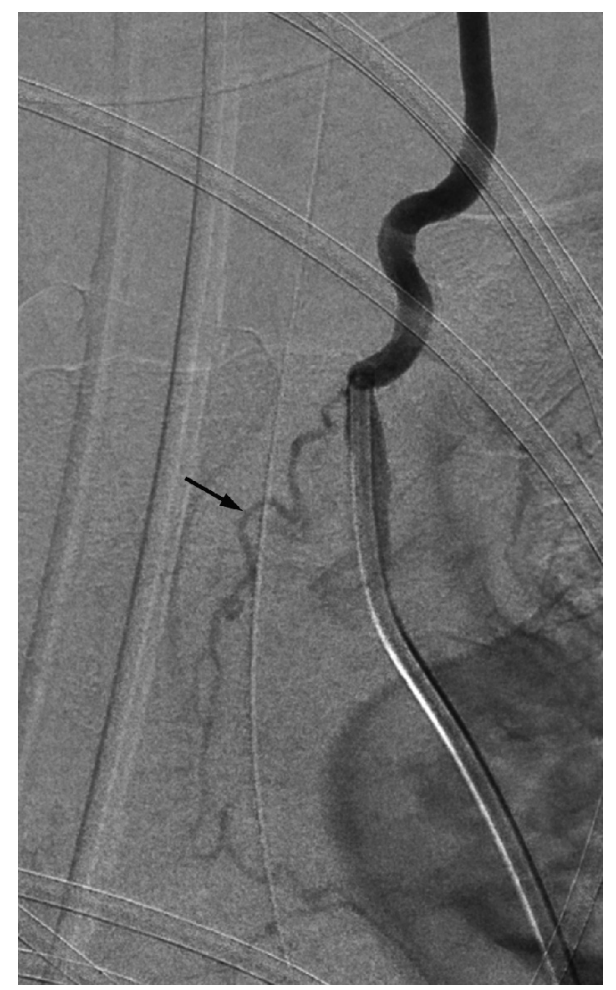

FIG 15. Vertebral artery variant in a 58-year-old woman. Left vertebral injection (posteroanterior projection) documents a prominent aberrant bronchial branch (arrow) of vertebral origin.

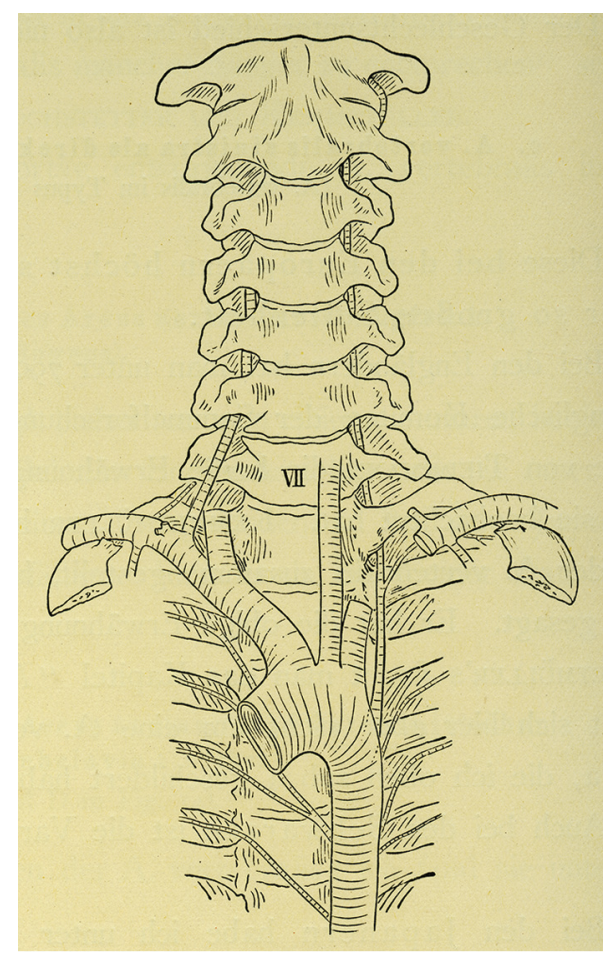

FIG 16. Reproduction of the original Fig 16 (Vol. 1, page 36) of Adachi. ${ }^{19}$ Adachi presents a left ascending thoracic VA originating from the aorta at the T3-T4 level and passing behind the head of the first rib to enter the first costotransverse space before continuing cranially as the left cervical vertebral artery.
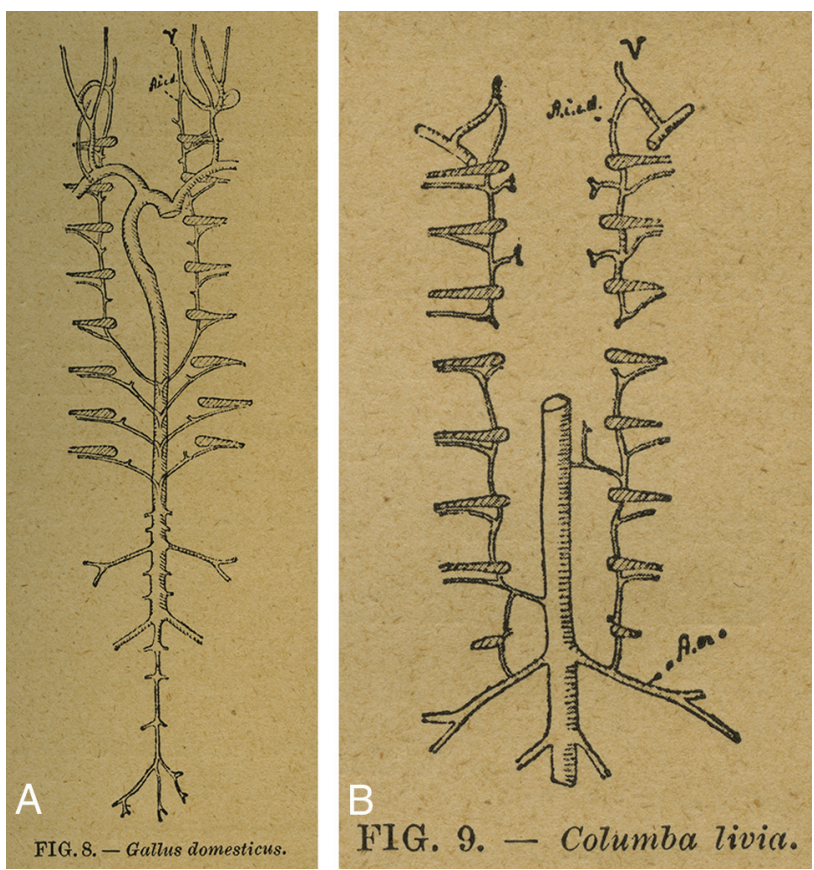

FIG 17. Examples of ascending and descending thoracic aortas in birds (from Pensa ${ }^{23}$ ). A, Bilateral ascending thoracic vertebral arteries in the chicken (Gallus domesticus); note a cranial anastomosis with the costocervical trunk. $B$, Bilateral descending thoracic vertebral arteries in the domestic pigeon (Columba livia). V indicates vertebral artery; Ai.c.d., arteria intercostalis communis descendens; A.cr., arteria cruralis.

sufficiency or supply an intracranial aneurysm or vascular malformation. They can also represent a source of embolic material, either of atheromatous or iatrogenic origin.

Finally, the possibility that a descending thoracic VA can contribute to the bronchial vascularization must be kept in mind when investigating a hemoptysis of elusive origin.

In summary, thoracic VAs are anastomotic chains similar to normal cervical VAs but extending through at least 1 costotransverse space. They can be divided into ascending and descending types that differ by their origin, course, and clinical implications.

Disclosures: Philippe Gailloud-UNRELATED: Grants/Grants Pending: Siemens*; Consultancy: Codman Neurovascular. Monica S. Pearl-UNRELATED: Grants/ Grants Pending: National Institutes of Health. * ${ }^{*}$ Money paid to the institution.

\section{REFERENCES}

1. Padget DH. Designation of the embryonic intersegmental arteries in reference to the vertebral artery and subclavian stem. Anat Rec 1954;119:349-56 Medline

2. Hochstetter F. Uber die Entwicklung der A. Vertebralis beim Kaninchen, nebst Bemerkungen über die Entstehung des Ansa Vieussenii. Morphol Jahrb 1890;16:572-86

3. Schmeidel G. Die Entwicklung der Arteria vertebralis des Menschen. Morphol Jahrb 1933;71:315-435

4. Walsham WJ. Abnormal origin and distribution of the upper seven right intercostal arteries, with remarks. J Anat Physiol 1882;16: 441-62 Medline

5. Krassnig M. Von der Arteria vertebralis thoracica der Säuger und Vögel. Beiträge und Referate zur Anatomie und Entwickelungsgeschichte 1913;49:523-609 CrossRef

6. Wenthe M, Waibl H, Meyer W. Some observations on the arteria vertebralis thoracica in the dog. Kasetsart Veterinarians 2009;19:65-69 
7. Dubreuil-Chambardel L. Traité des Variations du Système Artériel: Variations des Artères du Membre Supérieur. Paris: Masson et Cie; 1926:37-44

8. Lacout A, Khalil A, Figl A, et al. Vertebral arteria lusoria: a lifethreatening condition for oesophageal surgery. Surg Radiol Anat 2012;34:381-83 CrossRef Medline

9. Higashi N, Shimada $H$, Simamura E, et al. Right vertebral artery as the fourth branch of the aortic arch. Anat Sci Int 2008;83:314-18 CrossRef Medline

10. Lemke AJ, Benndorf G, Liebig T, et al. Anomalous origin of the right vertebral artery: review of the literature and case report of right vertebral artery origin distal to the left subclavian artery. AJNR Am J Neuroradiol 1999;20:1318-21 Medline

11. Sakamoto $H$. A case of the right vertebral artery as the last branch of the aortic arch (author's transl) [in Japanese]. Kaibogaku Zasshi 1980;55:503-08 Medline

12. Mukkannavar SB, Kuthe SA, Mishra AK, et al. Aberrant right vertebral artery from descending thoracic aorta. Ann Thorac Surg 2013; 96:1074-76 CrossRef Medline

13. Hsu DP, Alexander AD, Gilkeson RC. Anomalous vertebral artery origins: the first and second reports of two variants. J Neurointerv Surg 2010;2:160-62 CrossRef Medline

14. Koenigsberg RA, Pereira L, Nair B, et al. Unusual vertebral artery origins: examples and related pathology. Catheter Cardiovasc Interv 2003;59:244-50 CrossRef Medline

15. His W. Anatomie Menschlicher Embryonen, III: Zur Geschichte der Organe. Leipzig: Verlag von F.C.W. Vogel; 1885:193
16. Kadyi H. Über die Blutgefässe des Menschlichen Rückenmarkes Lemberg: Gubrynowicz \& Schmidt; 1889:26

17. Charpy A. Système Nerveux. Paris: Masson et Cie; 1902

18. Kappers A, Strasburger EH, Addens JL. Anatomie Comparée du Système Nerveux. Harleem: Bohn; 1947:532

19. Adachi B. Das Arteriensystem der Japaner. Kyoto: Kaiserlich-japanische Universität zu Kyoto, in kommission bei "Maruzen Co.”; 1928: 33-36, 191-92

20. Barkow HC. Die Angiologische Sammlung im Anatomischen Museum der Königlichen Universitätzu Breslau. Breslau: Hirt; 1869:XL-LI

21. Bühler A. Varietät der ersten fünf intercostalarterien. Gegenbaurs Morphologisches Jahrbuch 1904;32:189-94

22. Quain R, Maclise J. The Anatomy of the Arteries of the Human Body, with its Applications to Pathology and Operative Surgery: In Lithographic Drawings with Practical Commentaries. London: Taylor and Walton; 1844:142 (Plate 22)

23. Pensa A. Studio sulla morfologia e sullo sviluppo della arteria intercostalis suprema e delle aa. intercostales. Ricer Lab Anat Univ Roma 1905;11:33-142

24. Newton T, Mani R. The vertebral artery. In: Newton T, Potts D, eds. Radiology of the Skull and Brain: Angiography. Vol 2. Book 2. St. Louis: Mosby; 1974:1659-709

25. Chiras J, Launay M, Gaston A, et al. Thoracic vertebral artery: an anomaly of the vertebral artery. Neuroradiology 1982;24:67-70 CrossRef Medline

26. Bremer JL. The origin of the renal artery in mammals and its anomalies. Am J Anat 1915;18:179-200 CrossRef 